\title{
The free food (contrafreeloading) phenomenon: A review and analysis
}

\author{
STEVE R. OSBORNE \\ Arizona State University, Tempe, Arizona 85281
}

\begin{abstract}
Animals will perform an operant response to obtain food when abundant free food is available. These data have implications for current learning theories, especially in terms of the motivational variables associated with such behavior. The present paper reviews the literature and provides an analysis that suggests that responding for food in the presence of free food is importantly controlled by stimulus change attendant upon response-dependent food presentation. This apparent stimulus-reinforcer effect on behavior is compared to that observed in other areas of animal learning research that include preference between schedules of responsedependent and response-independent reinforcement, preference between schedules of signaled and unsignaled reinforcement, autoshaping and automaintenance, and self-reinforcement in animals.
\end{abstract}

When an animal is provided a choice between making an operant response to obtain food or by eating it from a source of continuously available free food, a curious thing happens. Animals not only acquire and continue to make the operant response, but they often appear to "prefer" the responsedependent food. That animals respond for food in the presence of identical free food is by now a wellestablished finding in the experimental literature.

Behavior has been maintained on both fixed-ratio (Alferink, Crossman, \& Cheney, 1973; Atnip \& Hothersall, 1973; Carder \& Berkowitz, 1970; Davidson, 1971; Hothersall, Huey, \& Thatcher, 1973; Tarte \& Vernon, 1974) and variable-interval (Bilbrey, Patterson, \& Winokur, 1973; Neuringer, 1970; Rachlin \& Baum, 1972; Sawisch \& Denny, 1973) schedules of reinforcement when free food was concurrently available. Different strains of rats (Atnip \& Hothersall, 1973; Hothersall et al., 1973; Powell, 1974), rats with septal and ventromedial hypothalamic lesions (Singh, 1972a), mice (Pallaud, 1971), chickens (Duncan \& Hughes, 1972), pigeons (Neuringer, 1969, 1970), crows (Powell, 1974), cats (Koffer \& Coulson, 1971), gerbils (Lambe \& Guy, 1973), Siamese fighting fish (Baenninger, \& Mattleman, 1973), and humans (Singh, 1970; Singh \& Query, 1971; Tarte, 1972) have been shown to work for reinforcers when equivalent free reinforcers were available. Although food reinforcers typically have been used, the phenomenon also has been

I thank L. Meyerson, S. Parkinson, and members of the "Glass Bead Gang," especially P. Killeen, for their helpful comments on an earlier draft of this paper, and Ada Cardenas for her help in preparing the manuscript. Reprints may be obtained from $\mathrm{S}$. Osborne, Department of Psychology, Arizona State University, Tempe, Arizona 85281. demonstrated with both water (Knutson \& Carlson, 1973; Powell, 1974; Robertson \& Anderson, 1975; Taylor, 1972, 1975) and sucrose solution reinforcers (Carder, 1972; Tarte, Townsend, Vernon, \& Rovner, 1974). Although not food deprived, rats (Davidson, 1971; Kopp, Bourland, Tarte, \& Vernon, 1976; McLaughlin, Kleinman, \& Vaughn, 1973; Tarte \& Synder, 1972), pigeons, (Bilbery et al., 1973; Neuringer, 1969; Wallace, Osborne, Norborg, \& Fantino, 1973) and chickens (Duncan \& Hughes, 1972) have continued to respond for food in the presence of free food.

Two separate, but related, issues are involved in the free food phenomenon (D'Amato, 1974; Taylor, 1972). First, under what conditions, i.e., to what extent, will animals "work" for food when free food is available? Second, do animals prefer to work for food when free food is available? In attempting to address the second issue, free food experiments frequently have been oriented towards specifying the preference relationship between free and responsedependent food. Preference for a food source exists when the proportion of food obtained from that source exceeds $50 \%$ of the total food obtained during a session. The data from studies of preference often vary enormously; some studies report a large preference for response-dependent food, others report an equally large preference for free food (cf. Carder \& Berkowitz, 1970; Taylor, 1972). Inconsistency of results from similar studies, coupled with difficulty in specifying the variables that control free food responding, may be responsible for the paucity of attempts to integrate free food data into existing theory, or to relate it to other areas of research in animal learning. However, recent research suggests new perspectives that allow an explanation of the phenomenon that not only is parsimonious with 
regard to existing free food data, but one that is relevant for other research areas as well.

\section{Definition of Free Food}

Some experimenters refer to intermittently available food presented on response-independent schedules as free food; however, food availability is specified by the experimenter. Free food in the present review refers to food that is both responseindependent and continuously available.

\section{THEORETICAL IMPLICATIONS}

\section{Least Effort}

Substantive experimental evidence suggests that animals tend to maximize reward while simultaneously minimizing effort. For example, rats prefer the shorter, less effortful path to a goal (DeCamp, 1920; Gengerelli, 1930; Kuo, 1922; Logan, 1960; Thompson, 1944; Tolman, 1955; Waters, 1934; Yoshioka, 1929). More recently, Herrnstein (1958) showed that pigeons permitted to choose between responding for food on different fixed-ratio schedules of reinforcement that were concurrently available invariably chose the smaller ratio schedule. The least effort hypothesis, as exemplified by these data, occupies a central position among most current learning theories (e.g., Ferster \& Skinner, 1957; Hull, 1943; Tolman, 1955).

Although some studies have found that animals make the least effortful response (see Lewis, 1965, for a review), other studies suggest either that response effort has little effect on choice between similar rewards or that the more effortful response is preferred (Collier \& Jennings, 1969; Jennings \& Collier, 1970; Kanarek \& Collier, 1973). That animals respond for reinforcers when abundant free reinforcers are available appears particularly difficult to reconcile with least effort concepts, especially when many responses per reinforcement are emitted (e.g., Neuringer, 1970).

\section{Response Dependency}

The major tenet of reinforcement theory is that reinforcement increases the probability that those responses which precede it will recur (Skinner, 1938, 1948). Arranging to have reinforcers dependent upon a response insures that the response will occur in close temporal proximity to reinforcement and allows the reinforcement process to operate at an optimal level. One way to assess the functional role of response dependencies is by scheduling reinforcers independently of behavior. Differences between behavior initiated or maintained by schedules of response-dependent and response-independent reinforcement can then be attributed to the presence or absence of an explicit response-reinforcer depen- dency. Brown and Jenkins (1968) found that experimentally naive pigeons came to peck a briefly lighted response key when keylight offset was followed by response-independent food. This "autoshaping" phenomenon has been shown with a number of nonavian species (see Hearst \& Jenkins, 1974) and appears to persist when responses result in reinforcer omission (Stiers \& Silberberg, 1974; Williams \& Williams, 1969).

The acquisition and maintenance of responding on response-independent schedules is not easily accounted for by reinforcement theory (cf. Bindra, 1974; Bolles, 1972), despite the suggestion that responding is superstitiously maintained by adventitious correlations between behavior and reinforcement (Herrnstein, 1966; Zeiler, 1968).

The acquisition and maintenance of foodacquiring responses when free food is available also challenges a reinforcement analysis. If reinforcement strengthens those behaviors which precede it, then free food should reinforce nonresponding (cf. Gibbon, Berryman, \& Thompson, 1974). Making a specific response for food in the presence of free food appears to be another example of behavior inadequately accounted for by reinforcement theory.

\section{RESPONDING FOR REINFORCERS IN THE PRESENCE OF FREE REINFORCERS}

In the premier experiment (Jensen, 1963), rats were shaped to leverpress for food pellets. Following 40 , $80,160,320,640$, or 1,280 continuously reinforced responses, a cup of free pellets was placed in the rear of the chamber. Jensen found that in one 40-min session the proportion of pellets obtained by leverpressing increased as a logarithmic function of the number of reinforced prechoice responses. Rats that received 40 reinforced responses prior to choice testing responded for about $20 \%$ of their food, whereas rats that received 1,280 reinforced responses before choice testing responded for $75 \%$ of their food. This finding was subsequently extended by Neuringer (1969). After shaping the keypeck response and receiving seven training sessions on CRF, two pigeons were housed in chambers where food was available either by keypecking or from a cup of free food located in the rear of the chamber. Although food was continuously available, these animals emitted approximately 420 and 1,200 responses per day, respectively, for food. A similar finding was reported for two rats, although the average number of responses was lower than for the pigeons. Conditions were then employed to control for the possible reinforcing effects of stimulus feedback associated with response-dependent food presentation. For one pigeon, a transparent shield was placed across the feeder opening, for the other the grain hopper was 
emptied, and for the rats, responses produced only the auditory feedback provided by the pellet dispenser. In all cases, responding decreased to nearly zero. Therefore, the maintenance of responding did not appear attributable to the reinforcing effect such stimulus feedback might have acquired as a result of pairing with food presentations or to the reinforcing properties of stimulus feedback alone. In a second experiment, Neuringer (1969) showed that responding could not be attributed to habit strength of a previously learned response or to special properties of the keypeck: Two experimentally naive pigeons lived in their chambers where grain was dependent on an operant response or available from a cup of free food. For one pigeon, the response was the depression of a lever, for the other a keypeck. In both instances, pigeons learned, without prior shaping, to respond for food and continued to respond despite the availability of free food.

It also has been shown that rats continuously housed in a chamber with free food available readily acquire and maintain a food-producing operant response (Coburn \& Tarte, 1976; Kopp et al., 1976; McLaughlin et al., 1973). Similarly, Baeninger and Mattleman (1973) found that Siamese fighting fish acquired and continued to emit an operant response that produced a mirror to which the fish could display, although a free mirror was continuously present. Therefore, responding for reinforcers in the presence of free reinforcers includes both the acquisition and the maintenance of behavior.

\section{Schedule of Reinforcement}

In the Jensen and Neuringer studies, responses were continuously reinforced. Responding also has been maintained on intermittent schedules of reinforcement when free food was concurrently available. Carder and Berkowitz (1970) preceded choice testing with three sessions of free food training and then six sessions of barpress training. They found that when only 1 or 2 responses were required per reinforcement, rats responded for $80 \%-100 \%$ of their food. However, when the response requirement was increased to 10 , preference for responsedependent food decreased to 10\%-30\%. Tarte and Vernon (1974) investigated barpressing for food across a greater range of fixed-ratio schedules and found a linear decrease in preference for responsedependent food as the ratio was increased from FR 1 $(65 \%)$ to FR $21(11 \%)$.

Free food responding also has been demonstrated on aperiodic schedules of reinforcement. Neuringer (1970) found that pigeons emitted over 40 keypecks per reinforcement when keypecks were reinforced following irregular time intervals that averaged $1 \mathrm{~min}$ (VI 1-min schedule) despite the availability of free food. Similarly, Rachlin and Baum (1972) showed that pigeons continued to respond for food on a VI 3-min schedule when free food was available. Although Neuringer (1970) and Rachlin and Baum (1972) used well-trained pigeons maintained at $80 \%$ of their free-feeding weights, such conditions are not necessary for the maintenance of responding on intermittent schedules of reinforcement. Bilbrey et al. (1973) found that pigeons allowed continuous access to free food, both in the home cage and during experimental sessions, continued to respond for food on VI 3-min and VI 30-sec schedules. In a second study, they showed that previous experience with keypecking for grain had only minor effects on the rate of responding maintained by a VI $30-\mathrm{sec}$ schedule.

Sawish and Denny (1973) also reinforced pigeons' keypecks for food on a VI 1-min schedule, but they made the opportunity to respond for food dependent on eating or not eating free food. They found that eating free food increased when the opportunity to respond was dependent on eating free food and decreased when the opportunity to respond was dependent on not eating free food for a period of 30 or $60 \mathrm{sec}$. Sawisch and Denny suggested their data were evidence of the operation of the Premack principle (cf. Premack, 1959) in a free food situation; that is, the use of a high-probability response (keypecking) to reinforce a low-probability response (eating free food).

\section{Preference for Free Food}

Despite the apparent robustness of the phenomenon and the suggestion of earlier research that animals prefer response-dependent food, subsequent studies produced conflicting data. In one experiment (Taylor, 1972), choice testing was preceded by 1,000 continuously reinforced barpresses and then a single session where only free food was available. During the initial test sessions of $20 \mathrm{~min}$, rats responded for over $50 \%$ of their food; however, by the 15 th test session, preference for response-dependent food decreased to $20 \%$. Taylor suggested that the difference between his and Jensen's data was that Jensen conducted only one session of preference testing and hence failed to observe the changes toward free food that occur over consecutive sessions. An alternative explanation for the inconsistency in preference is that Taylor used sessions of shorter length. Tarte and Snyder (1973) used a procedure similar to that of Taylor, but conducted 10 1-h sessions of preference testing. They found a consistent preference for response-dependent food with no systematic change in preference evidenced across consecutive sessions. That Taylor allowed prechoice training with free food also may have affected preferences (see Food Training Procedures below). Nonetheless, other studies support the find- 
ing that animals prefer free food. For example, two direct replications of the Carder and Berkowitz (1970) study showed that rats preferred free over response-dependent food when responses were reinforced by FR 1, FR 2, and FR 10 schedules (Atnip \& Hothersall, 1973; Hothersall et al., 1973). Koffer and Coulson (1971) also found that cats, given a choice between responding for fish or obtaining it freely, consistently chose free fish, and Lambe and Guy (1973) found that both rats and gerbils preferred free over response-dependent food.

\section{Reinforcer-Motivational Variables}

The ability of qualitatively different reinforcers to maintain responding in the presence of equivalent, free reinforcers also has been studied. Choice proportions vary between experiments, but it has been demonstrated that animals show a stronger preference for response-dependent food reinforcers than for response-dependent water reinforcers under conditions of continuous reinforcement (Carder, 1972; Roberts \& Anderson, 1975; Tarte et al., 1974; Taylor, 1972), and intermittent reinforcement (cf. Tarte \& Vernon, 1974; Taylor, 1975). Carder (1972) exposed rats to a situation where either water or sucrose solution reinforcers were available freely or by barpressing. He found that rats obtained $83 \%$ of their sucrose reinforcers but only $23 \%$ of their water reinforcers by barpressing. Similarly, Tarte et al. (1974) reported preferences of $79 \%$ and $54 \%$, respectively, for response-dependent food and response-dependent water reinforcers.

Altering the physical quality of the reinforcer also affects preference. Carder (1972) found that when both free and response-dependent reinforcers were adulterated with quinine, preference for responsedependent sucrose decreased as a function of adulteration level. Tarte et al. (1974) found that a nonnutritive reinforcer (saccharin) maintained little responding with either food- or water-deprived rats when saccharin was freely available, and Davidson and Davis (1975) found that the proportion of food acquired by barpressing decreased following injections of known anorexic drugs.

Robertson and Anderson (1975) investigated the effects of varying the magnitude of the responsedependent reinforcer using both food (20- or $45-\mathrm{mg}$ pellets) and water $(0.01$ or $0.1 \mathrm{cc})$ reinforcers. They reported that differences in choice proportions across reinforcer magnitudes were not statistically significant. However, no prechoice exposure was provided to the free reinforcers and all three choice sessions were included in their data analysis. A close examination of the data shows that preference for smallmagnitude response-dependent reinforcers decreased linearly over sessions, whereas preference for largemagnitude response-dependent reinforcers remained fairly constant across sessions. By the third choice session there was a clear difference between the groups: animals in the food-reinforcer group barpressed for $14 \%$ (20-mg pellets) and 40\% (45-mg pellets) of their reinforcers; rats in the waterreinforcer group barpressed for $4 \%(0.01 \mathrm{cc})$ and $31 \%(0.1 \mathrm{cc})$ of their reinforcers. Thus the data of Robertson and Anderson suggest that reinforcer magnitude exerts a strong effect on preference. Moreover, it appears that there is a greater preference for response-dependent food, relative to response-dependent water reinforcers, even when the magnitude of the water reinforcer (by weight) is twice that of food; that is, $0.1 \mathrm{cc}$ of water represents a larger magnitude reinforcer than does a $45-\mathrm{mg}$ food pellet, yet under these magnitude conditions rats barpressed for a greater proportion of their food reinforcers.

Variation in the magnitude of water reinforcers may account for some of the variability in previously reported choice data. For example, Powell (1974) and Taylor $(1972,1975)$ both reported that rats barpressed for $5 \%$ or less of their water reinforcers, but they used response-dependent reinforcers of relatively small magnitude $(0.01-0.02 \mathrm{cc})$. Alternatively, Carder (1972) and Tarte et al. (1974) found that rats barpressed for $26 \%$ and $54 \%$, respectively, of their water reinforcers when the magnitude of the responsedependent reinforcer was $0.1 \mathrm{cc}$. Knutson and Carlson (1973) reported that rats barpressed more for water reinforcers than for food reinforcers when equivalent free reinforcers were present. They used standard $45-\mathrm{mg}$ food pellets and $0.01 \mathrm{cc}$ of water as the response-dependent reinforcers. Therefore, although rats responded more for water reinforcers, they still may have obtained a larger proportion of their food reinforcers by responding (cf. Robertson \& Anderson, 1975).

In sum, preference for response-dependent reinforcements appears to be an increasing function of the effectiveness of the reinforcer, which depends upon reinforcer-motivational variables (cf. Bindra, 1974), such as rate and magnitude of reinforcement as well as the physical quality of the reinforcer. There also is a greater preference for response-dependent food compared to response-dependent water reinforcers when equivalent free reinforcers are available. This latter finding is consistent with other research (e.g., Fallon, Thompson, \& Schild, 1965) showing that water is a less potent reinforcer than food when deprivation duration and reinforcer weight are equated.

An indirect way to manipulate reinforcer effectiveness is by varying the severity of reinforcer deprivation. Given the above data, food deprivation and preference for response-dependent food might be expected to covary. In the single experiment in which 
food deprivation was varied systematically (Tarte \& Synder, 1972), preference for response-dependent food increased as food deprivation time was extended from 0 to $92 \mathrm{~h}$. Morgan, Einon, and Nicholas (1975) also found that rats deprived of food for $23 \mathrm{~h}$ responded for a significantly greater proportion of their food than rats fed immediately before a session. However, other researchers failed to detect similar deprivation effects.' Duncan and Hughes (1972) found no difference in the proportion of food chickens obtained by keypecking between conditions of continuous access to food and 22 -h food deprivation. Davidson (1971) trained rats to keypress for food on a multiple schedule of reinforcement. When the chamber was illuminated, every 10 th response produced reinforcement (FR 10) and extinguished the chamber illumination, signaling that response-dependent food was not available. Cessation of responding for $20 \mathrm{sec}(\mathrm{DRL} 20 \mathrm{sec}$ ) reinstated the chamber illumination and the FR 10 schedule. When free food was provided, it was consumed during the DRL component, but rarely during the FR component. Providing continuous access to food in the home cage eliminated within-session consumption of free food but failed to abolish keypressing in the FR component.

Several investigators (Davidson, 1971; Knutson \& Carlson, 1973; Mitchell, Scott, \& Williams, 1973; Robertson \& Anderson, 1975) noted that the probability of a response within an experimental session increases over time; free food typically is consumed during the first part of a session. It appears, then, that probability of responding and within-session food deprivation are inversely related. It remains possible that within- and between-session food deprivation have different effects on responding. Variables that control cessation of responding for food (or eating) are poorly understood (Morgan, 1974a). At present the effects of food deprivation on preference for response-dependent food are equivocal. However, variables other than "hunger drive" or food deprivation appear responsible for the maintenance of free food responding, since several reports have shown that animals may fail to consume up to $25 \%$ of the food they have responded for (Mitchell et al., 1973; Neuringer, 1969; Tarte \& Synder, 1973) and that considerable responding is maintained in the absence of food deprivation (e.g., Kopp et al., 1976; Neuringer, 1969; Wallace et al., 1973).

\section{Food Training Procedure}

Providing differential prechoice training with response-dependent food significantly increases preference for response-dependent food. As previously noted, preference for response-dependent food increases as a function of the number of prechoice reinforced responses (Jensen, 1963). McLaughlin et al. (1973) found that rats left in experimental chambers for 7 to 10 days acquired a barpress response with both free food and water continuously available. Although response rates initially were low, removal of the free reinforcers for $24 \mathrm{~h}$ increased barpressing tenfold once a choice between free and response-dependent food or water was reinstated. In a more systematic investigation of the effects of prechoice training, Tarte and Synder (1973) found that rats barpressed for $72 \%$ of their food following three free food sessions and six sessions of barpress training, but they barpressed for only $15 \%-20 \%$ of their food following equalized food training procedures.

Mitchell et al. (1973) suggested that the prechoice training schedule, per se, is a less important variable than the amount and/or recency of familiarity with the different food sources. After shaping, rats were allowed to make 140 continuously reinforced re sponses and were then given 10 training sessions. One group received seven sessions of barpress training followed by three sessions of free food training; a second group received the same distribution of training sessions, but in reverse order. When choice testing immediately followed barpress training rats barpressed for $50 \%$ of their food, but they barpressed for only $1 \%$ of their food when choice testing immediately followed free food training. A third group of rats given three alternating free and responsedependent food training sessions followed by four sessions of barpress training responded for $34 \%$ of their food. Thus preference for free food appeared to be an increasing function of the recency of free food training. However, free food training sessions were conducted with the response bar present but inoperable. Consequently, barpressing for food may have undergone extinction during free food training and the decreased preference for response-dependent food may have been due to the recency of extinction.

There also is some evidence that familiarity with the food containers (Mitchell et al., 1973; Mitchell, Williams \& Sutter, 1974; but see Carder \& Beckman, 1975 ) or the food substance (Carlson \& Riccio, 1976) affects preference. Mitchell et al. (1973) found that rats barpressed for $48 \%$ of their food when free food was placed in a novel container and response dependent food was presented in a familiar container, but they barpressed for only $1 \%$ of their food when conditions were reversed. Carlson and Riccio (1976) found that providing prechoice exposure to food pellets of the type used during experimental sessions, either in the home cage or in the test chamber, reduced subsequent preferences for response-dependent food. In a second experiment, it was shown that changing the flavor of both free and 
response-dependent pellets between conditions of prechoice training and testing decreased preferences for response-dependent food.

Stolz and Lott (1964) investigated the effects of prechoice training on a running response. Rats were trained to run an 8-ft straight alley for a single food pellet; then, during choice trials, a pile of 1,500 pellets was placed midway down the alley. Rats that received more prechoice training more often ran to the goalbox than animals given less training. However, two subsequent studies suggest that providing prechoice training for a running response increases preference for free food. Leung, Jensen, and Tapley (1968) allowed two groups of rats either 75 or 285 reinforced runs down a straight alley before giving them a choice between eating free food in the startbox or running the alley for a single pellet. They found that rats given fewer prechoice trials ate less free food and spent less time in the startbox before traversing the alley. Jensen, Leung, and Hess (1970), using a similar procedure, allowed three groups of rats 0,40 , or 285 reinforced runs before choice testing. They found that rats given no prechoice training spent less time eating free food before running the alley than rats given 40 or 285 prechoice trials; there was no significant difference between the latter two groups.

Free food experiments typically involve a choice between topographically dissimilar operants that lead to the same reinforcer. Larson and Tarte (1976) assessed the effects of prechoice training when the choice responses involved topographically similar operants. They found that rats initially preferred the longer of two paths to a goalbox in a T-maze if they were given more prechoice training with the longer path. However, over successive choice trials, preference for the shorter path increased to about $90 \%$. Rats given an equal number of prechoice trials for both paths preferred the shorter path from the outset of testing. Kleinman, McLaughlin, Gerard, Bosza, and Clipper (1976) found that rats consistently preferred the larger of concurrently available FR 1 and FR 3 schedules following differential training with the larger ratio schedule. Taken together these two studies suggest that prechoice training effects are transient if the difference in "effortfulness" between the two alternatives is large (e.g., running a path of 122 or $244 \mathrm{~cm}$; Larson \& Tarte, 1976) compared to the more enduring effects that result when the difference in effortfulness is small (e.g., barpressing on an FR 1 or FR 3 schedule or, perhaps, barpressing on an FR 1 schedule for pellets or obtaining them freely).

Several explanations have been proposed for the effects of prechoice food training. Mitchell and his associates suggested that the effect of food source familiarity on preference is due to a neophobic re- sponse of the rat. Wild rats tend to avoid strange food and strange food sources (Barnett, 1963); laboratory rats apparently share this disposition. That rats run over a pile of pellets in a straight alley (Stolz \& Lott, 1964) seems explicable by such an analysis. Rats prefer to eat in that part of the apparatus where they have been accustomed to eating; for example, they will carry food found in the stem of a maze to the goalbox before consuming it (Cohen-Salmon \& Blancheteau, 1967). On the other hand, Carlson and Riccio (1976) argued that during barpress training the reinforcer becomes a discriminative stimulus for the operant response that produces it (cf. Denny, 1971), and thereby maintains barpressing in the presence of free food. Yet another interpretation of the effects of prechoice food training was provided by Taylor (1975), who suggested that preference for response-dependent reinforcers results from a failure to discriminate between conditions of testing and training. He found that preference for response-dependent water reinforcers decreased whenever the response requirement was increased or decreased from its prechoice training value. The wide range of species, reinforcers, and procedures used in free "food" studies makes it difficult to ascribe the effects of training procedures to food source familiarity or discrimination effects. In many cases there is little to distinguish between such accounts because common predictions are often made by all. However, the discriminative stimulus hypothesis is consistent with data collected outside the free food area (cf. Rescorla \& Skucy, 1969) and it can more easily account for the effects of prechoice training when only a single food source is available (e.g., Kleinman et al., 1976). Nevertheless, of the studies reviewed, an explicit preference for response-dependent reinforcement was obtained only when no prechoice training for the free reinforcer was provided (e.g., Jensen, 1963) or when prechoice training procedures that favored responding were used (e.g., Carder \& Berkowitz, 1970). Together, these data help resolve the preference issue: animals appear to prefer response-dependent reinforcers only after asymmetrical food training procedures. However, the issue of why animals respond at all when free reinforcers are available is left unresolved.

\section{Stimulus Change}

Several recent experiments suggest that free food responding is maintained by stimulus changes correlated with response-dependent food presentation. Wallace et al. (1973) provided naive pigeons with a choice between two sources of free food. They found that when entries into one food source were accompanied by a change in ambient stimulus conditions, pigeons consistently preferred the food source associated with stimulus change. In a second experiment, 
two pigeons lived in experimental chambers where food was avilable by keypecking or from a cup of free food. Whenever keypecks produced both food and stimulus change associated with food presentation, more than 100 continuously reinforced responses were made per session. However, responding decreased to nearly 0 if stimulus change was presented contemporaneously with free food acquisition, and responses produced food without concomitant stimulus change. Alferink et al. (1973) trained pigeons to respond for grain on a FR 300 schedule and then propped up the grain hopper so that grain was available without responding. Responding was maintained when every 300 responses continued to produce the hopper light, but decreased to a low level when responses had no scheduled effect. Reinstating the hopper-light-on contingency returned responding to its previous rate. Responding appeared to be controlled by the response-dependent presentation of a stimulus (hopper light) previously associated with response-dependent food.

Osborne and Shelby (1975) extended these findings to a nonavian species. Following six alternating free and response-dependent food training sessions, rats were provided a choice between barpressing for pellets on CRF or obtaining them freely from a cup of 500 pellets. When a brief auditory and visual stimulus accompanied barpresses, these animals responded for $28 \%$ of their food; however, removal of the stimulus as a consequence of barpressing decreased responding to nearly zero. Subsequent conditions revealed that the amount of maintained responding, and consequently preference for responsedependent food, varied as a function of stimulus change conditions attendant upon response-dependent food presentation. For example, there was a significantly greater preference for response-dependent food when barpresses were accompanied by both auditory and visual feedback than when barpresses were accompanied by auditory or visual feedback alone.

A fortuitous example of the effects of stimulus change was provided by Mitchell et al. (1973). They allowed one group of rats a choice between barpressing for pellets or obtaining them freely from a pile of 300 pellets in an adjacent food dish. To control for the possible novel effect of bulk reinforcement (300 pellets), a second group of rats received a food dish that contained only 20 free pellets; an additional pellet was dispensed by the experimenter each time a free pellet was removed. Although both groups preferred free food, rats provided with free food accompanied by the sound of the pellet dispenser consumed less free food than rats provided free food without the sound of the feeder. In short, equating stimulus change conditions for both free and response-dependent food essentially eliminated barpressing.
Two explanations have been proposed for the effects of stimulus change in free food experiments. One suggests that stimulus change associated with response-dependent food serves as a conditioned reinforcer; the other maintains that stimulus change derives its reinforcing properties through sensory reinforcement effects.

\section{Conditioned Reinforcement}

Alferink et al. (1973) and Tarte and Synder (1972) suggested a conditioned reinforcement explanation of the free food phenomenon. Conditioned reinforcers are stimuli that acquire their reinforcing property through association with an unconditioned reinforcer. Two sources of stimulus change associated with food presentation in free food experiments are those afforded by the response operandum and the food delivery system, and any scheduled stimulus changes. Through repeated pairing with food presentation, stimulus change may acquire conditioned reinforcing properties. Responding for food in the presence of free food might be attributed to the combined reinforcing effectiveness of responseproduced food and conditioned reinforcement provided by stimulus change. Neither responseproduced food alone (Osborne \& Shelby, 1975; Wallace et al., 1973) nor resonse-produced stimulus change alone (Davidson, 1971; Duncan \& Hughes, 1972; Enkema, Slavin, Spaeth, \& Neuringer, 1972; Neuringer, 1969; Osborne \& Shelby, 1975; Tarte, 1974) are sufficient to maintain responding when free food is available. Yet, when responses produce both food and stimulus change, many responses are emitted. The failure to maintain responding with stimulus change alone is consistent with the finding that stimuli which serve as conditioned reinforcers of ten lose their effectiveness when primary reinforcement is withheld (Kelleher \& Gollub, 1962).

\section{Sensor Reinforcement}

Response-dependent sensory reinforcers unrelated to primary appetitive reinforcers are reinforcing (cf. Kish, 1966). Naive pigeons acquire and maintain a keypeck response when the sole consequence of responding is a change in ambient stimulus conditions or a change in response key color (Appel, 1963; Herrnstein \& Loveland, 1972). Osborne and Shelby (1975) suggested that animals in free food experiments respond for food plus stimulus change not because stimulus change is a conditioned reinforcer, but because the reinforcing value of stimulus change increases in the presence of other more potent primary reinforcers. Sensory reinforcement effects may interact with the primary reinforcement effects of response-dependent food such that the total reinforcement obtained by responding is sufficient to maintain responding when free food is available.

In all the free food experiments reviewed here, 
stimulus change was paired with food presentation. This makes it difficult to distinguish between conditioned and sensory reinforcement effects, because many of the variables that affect the reinforcing effectiveness of conditioned reinforcers have a similar effect on the reinforcing potential of sensory reinforcers. However, some free food data appear more amenable to a sensory reinforcement analysis. First, if conditioned reinforcers acquire their reinforcing properties through repeated association with primary reinforcers, then acquisition of a foodobtaining response in the presence of free food (Kopp et al., 1976; Neuringer, 1969) is difficult to explain by conditioned reinforcing effects of stimulus change. On the other hand, sensory, or unconditioned reinforcing stimuli, need no prior exposure to affect behavior and they presumably would be reinforcing from the outset. Second, Tarte and Synder (1973) required that 0,25 , or 50 continuously reinforced responses occur prior to placing free food in the chamber. During the ensuing choice period, responding decreased as the number of reinforced prechoice responses increased. Although the change was not statistically significant, it is noteworthy that this requirement should have increased the conditioned reinforcing strength of stimulus change because of the extra number of stimulus-food pairings; yet preference for response-dependent food decreased. Alternatively, with such a procedure, sensory reinforcement effects might have undergone partial satiation. Finally, following a condition where no stimulus feedback accompanied responding, Osborne and Shelby (1975) exposed some rats to a condition where an auditory stimulus accompanied responding; for others a visual stimulus accompanied responding. Addition of the auditory stimulus increased responding, although this stimulus previously had not been associated with food presentation. Subsequently, when both auditory and visual feedback accompanied response-produced food, responding increased above the level maintained by either auditory or visual feedback alone. Egger and Miller $(1962,1963)$ have shown that, when stimuli provide redundant information about impending reinforcement, such stimuli do not become conditioned reinforcers even though they are temporally contiguous with reinforcement. Adding stimulus feedback from a different stimulus modality, as Osborne and Shelby did, added no information to the situation, yet responding increased. This squares with the fact that increasing the complexity, the inconstancy, or the novelty of a sensory reinforcer increases its reinforcing potential (Barnes \& Baron, 1961; Dember, 1956; Welker \& King, 1962).

Sensory reinforcement also may account for some of the differences in acquisition and maintenance of free-food responding between animals reared in different environments. Coburn and Tarte (1976) reared groups of rats in either stimulus-impoverished or stimulus-enriched environments and then housed them in chambers where both free and responsedependent food were avilable. Animals in the impoverished group readily acquired the barpress response and consistently responded for about $60 \%$ of their daily food intake; rats in the enriched group responded at a low level throughout the experiment and earned less than $1 \%$ of their food by responding. Morgan et al. (1975) assessed choice behavior of impoverished and enriched rats on a concurrent schedule of reinforcement. On one side of a chamber, leverpresses produced a food pellet once every $30 \mathrm{sec}$; on the other side of the chamber, a pellet was delivered once every $30 \mathrm{sec}$, independently of the animal's behavior. In this situation there was no difference in the choice behavior of impoverished and enriched rats. When these same rats were subsequently provided a choice between free food and leverpressing for pellets on a schedule of continuous reinforcement, the impoverished rats responded for $42 \%$ of their food whereas animals in the enriched group responded for only $19 \%$ of their food. In the first experiment, identical stimulus change accompanied both response-dependent and responseindependent pellet deliveries, but in the second experiment, stimulus change only accompanied response-dependent pellets. Therefore, differences in preference behavior between enriched and impoverished animals were evident only when differential stimulus change accompanied responseproduced pellets.

Davis, Beighley, Libretto, Mollenhour, and Prytula (1975) also found that rats reared in stimulusdeprived environments preferred response-dependent food, whereas rats reared in either normal or stimulusenriched environments preferred free food (but see Tarte, Townsend, \& Vernon, 1973).

Numerous behavioral differences exist between animals reared in impoverished and enriched environments (cf. Morgan, 1973, Morgan et al., 1975; Wallace, 1974). For example, impoverished rats show heightened levels of exploratory behavior and are slower to habituate to environmental (sensory) stimuli. It might be argued, then, that impoverished rats are more likely to respond for stimulus change or satiate more slowly than normals. This interpretation is not only consistent with the data of Coburn and Tarte (1976) and Morgan et al. (1975), but also is supported by a large body of literature which shows that the ability of sensory reinforcers to maintain responding is directly related to antedating stimulus deprivation conditions (cf. Fowler, 1971; Kish, 1966).

Although a sensory reinforcement explanation of stimulus change appears to account for much of 
the data, it does not account for the effects of prechoice training on preference. Here a conditioned reinforcement explanation is more consistent; that is, the strength of a conditioned reinforcing stimulus presumably increases with repeated stimulusreinforcer pairings.

\section{Controlling Variables}

Prechoice food training appears to affect preference between free and response-dependent food. However, differential prechoice training with response-dependent food is neither necessary nor sufficient for the acquisition or maintenance of responding for reinforcers in the presence of equivalent free reinforcers. Although food source familiarity or discriminative stimulus hypotheses may aid our understanding of the effects of prechoice training on preference, neither adequately accounts for the wide range of data reviewed here. First, differential prechoice training with responsedependent food does not insure preference for response-dependent food (Atnip \& Hothersall, 1973; Hothersall et al., 1973). Second, both rats and pigeons readily acquire an operant response for food or water reinforcers in the presence of equivalent free reinforcers (Kopp et al., 1976; McLaughlin et al., 1973; Neuringer, 1969), and continue to respond for reinforcers after equalized training procedures (Osborne \& Shelby, 1975; Tarte \& Synder, 1973). Finally, prechoice training appears to have only a minor effect on the rate of maintained responding in avian species (Bilbrey et al., 1973; see also Duncan \& Hughes, 1972). Alternatively, responding fails to develop unless differential stimulus change accompanies response-dependent food presentation (Mitchell et al., 1973); well-trained responses are extinguished readily if the stimulus change that normally accompanies response-dependent food presentation is withheld (Alterink et al., 1973; Wallace et al., 1973); and preference for responsedependent food appears to vary systematically as a function of the stimulus change conditions that accompany responses. Despite the present difficulty in ascribing a conditioned or sensory reinforcement function to stimulus change, it seems clear that responding for reinforcers when physically equivalent reinforcers are freely available is attributable to the differential reinforcement afforded by responsedependent food and attendant stimulus change. However, this appears to be an interactive effect; that is, the amount of responding maintained by food-plus-stimulus change cannot be predicted by a simple additive combination of the amount of responding maintained by each (Osborne \& Shelby, 1975; cf. Herrnstein \& Loveland, 1972).

In considering the interactive effect of food and stimulus change, several general statements appear to encompass existing data collected within the free food paradigm: The tendency to respond for reinforcers when physically equivalent free reinforcers are available (a) increases whenever reinforcer effectiveness increases, and/or when the reinforcing effectiveness of the stimulus change associated with its presentation increases, and (b) decreases whenever the reinforcing effectiveness of the reinforcer or the stimulus change associated with its presentation decreases. The reinforcing effectiveness of primary reinforcers like food and water is determined by a host of variables that include the rate and magnitude of reinforcement, the physical quality of the reinforcer, and reinforcer deprivation. Several variables that contribute to the reinforcing effectiveness of sensory reinforcers include the complexity, novelty, and inconstancy of the stimulus change as well as antedating stimulus deprivation conditions. Although the emphasis here is on the sensory reinforcing properties of stimulus change, a comparable argument can be made for the conditioned reinforcing properties of stimulus change, i.e., the strength of a conditioned reinforcing stimulus presumably covaries with the reinforcing effectiveness of the primary reinforcer with which it is associated. It remains possible that stimulus change serves both a conditioned and a sensory reinforcement function.

\section{Interexperiment Variability}

Considerable interexperiment variability has occurred in studies of preference between free and response-dependent food. Much confusion and difficulty in integrating free food data into existing theory has resulted. Methodological differences are an obvious source of variance, although the problem is complicated further by the use of different dependent measures. Data have been reported as number of responses (Neuringer, 1969), proportional amounts of free and response-dependent food consumed (Carder \& Berkowitz, 1970), and latency to eat free or response-dependent food (Jensen et al., 1970; Koffer \& Coulson, 1971). Nonetheless, interexperiment variability in preference data appear to be attributable largely to differences in prechoice food training procedures and to stimulus change conditions associated with response-dependent food, although session duration differences and the brevity of choice testing may also contribute to variability. Differences in stimulus change conditions between experiments may be no greater than those resulting from apparatus differences. Such differences may nonetheless affect choice behavior and thereby provide a possible explanation for differences in obtained preferences between experimenis that used seemingly identical procedures (cf. Atnip \& Hothersall, 1973; Carder \& Berkowitz, 1970). 


\section{RELATED RESEARCH}

\section{Response-Independent and Response- Dependent Reinforcement}

Studies by Morgan (1974b) and Singh (1970) typically have been included in evaluations of the free food phenomenon. Because "free food" was not continuously available in these studies, they differ from the procedural arrangement used in other free food studies. Singh (1970) allowed rats a choice between barpressing for pellets on one side of a chamber or receiving free pellets on the other side. "Free pellets" were dispensed only if the animal remained in the free food compartment for a time interval equated with the average obtained interreinforcement interval of concurrently available response-dependent food. When barpresses were reinforced on fixed-ratio schedules (FR 1, FR 3, and FR 11), rats responded for about $70 \%$ of their food, and they continued to prefer response-dependent food even when free food was available at a faster rate.

The finding of a consistent preference for responsedependent food appears inconsistent with the stimulus change hypothesis outlined above inasmuch as stimulus change presumably was equalized for both food sources. However, free pellets could arrive when the rat was anywhere in the free food compartment, whereas on the response-dependent side the rat had to be in contact with the response lever and in close physical proximity to the food cup at time of pellet delivery. Consequently, the occurrence of stimulus change and food acquisition could be separated temporally on the reponse-independent side but presumably would occur in close temporal proximity on the response-dependent side. Within a similar paradigmatic arrangement, Morgan (1974b) found that food consumption latencies for responseindependent food were much higher than for response-dependent food. Morgan's data suggest that the temporal relationship between stimulus change and food acquisition may be an important variable. When Morgan equated stimulus change conditions attendant upon food acquisition, he found that rats responded for only $30 \%-40 \%$ of their food. The obtained rate of reinforcement (number of pellets/time) was higher on the responsedependent side and yielded a close approximation to the "matching law" (Herrnstein, 1970). When an added stimulus signaled that a barpress would be reinforced, rate of reinforcement and preference for that side increased. When rate of reinforcement and stimulus conditions were equalized for both food sources, an equivalent amount of food was obtained from each. In short, the Singh and Morgan data are consistent with other research (Killeen, 1968; Moore \& Fantino, 1975) which indicates that animals are indifferent between response-independent and response-dependent schedules of reinforcement when the rate of reinforcement is constant for each; deviations from indifference appear to be attributable to asymmetrical stimulus conditions. That animals show a near-exclusive preference for free over response-dependent food when stimulus change conditions are equalized may result from differences in rate of reinforcement.

\section{Signaled Reinforcement}

Animals and humans permitted to choose between a primary reinforcer preceded by a signal and the same reinforcer unsignaled prefer the signaled reinforcer (Cantor, 1971; Cantor \& LoLordo, 1970, 1972; Furedy \& Klajner, 1972; Lewis, Lewin, Muehliesen, \& Stoyak, 1974; but see Hershiser \& Trapold, 1971). Cantor and LoLordo (1970) administered 0.5 -sec trains of electrical stimulation of the brain (ESB) to rats according to a variable-time 1 -min schedule. The rats were placed in a shuttlebox and provided a choice between receiving ESB preceded by a signal on one side of the chamber and the simultaneous presentation of ESB and signal on the other. They found that rats spent approximately $70 \%$ of their time in that part of the chamber where ESB was preceded by a signal. Lewis, Lewin, Muehliesen, and Stoyak (1974) reinforced pigeons' keypecks with grain on a VI 1-min schedule. A peck to a second, concurrently available changeover key produced a VI 1-min schedule for $1 \mathrm{~min}$, during which reinforcement was preceded by a 5 -sec tone stimulus. Under this procedure, pigeons pecked the changeover key at a rate sufficient to maintain the signaled schedule in effect $90 \%$ of the time. In studies of signaled reinforcement, a stimulus precedes and is invariantly correlated with reinforcement. In free food experiments, a response is followed by a brief stimulus and food. Despite procedural differences between the two paradigms, the stimulus effects on behavior are similar. Differentially adding a stimulus that precedes reinforcement in a choice situation increases preference for that alternative.

\section{Autoshaping and Automaintenance}

Experimentally naive animals "autoshape" to stimuli that signal response-independent reinforcement (e.g., Brown \& Jenkins, 1968; Peterson, Ackil, Frommer, \& Hearst, 1972) and still respond when responses prevent the delivery of reinforcement (Stiers \& Silberberg, 1974; Williams \& Williams, 1969). Autoshaping and free food experiments differ in terms of alternative sources of reinforcement, but are similar because responding in both cases is initiated and maintained in a situation where reinforcers are available independently of behavior. 
In a recent monograph, Hearst and Jenkins (1974) suggested that animals orient towards, approach, and make contact with stimuli that signal impending reinforcement and avoid or withdraw from stimuli that signal reinforcer unavailability, a behavioral process they call "sign-tracking." Autoshaping and related phenomena are attributed to stimulusreinforcer effects; i.e., stimuli that precede reinforcement elicit approach and contact behavior to those stimuli. Unconditioned stimulus events also appear to elicit exploratory reactions of approach, investigation, and contact behavior (cf. Fowler, 1971). Such "sensory reinforcers" appear to have an effect on the initiation and maintenance of responding when free food is available, and they may contribute to the initiation and maintenance of autoshaped responses. Herrnstein and Loveland (1972) found that naive pigeons autoshaped to a stimulus change reinforcer. They concluded that "this kind of reinforcement (stimulus change) would by itself, make possible the phenomenon of autoshaping." However, the phenomenon is greatly enhanced by correlating food with stimulus change. Similarly, Blanchard and Honig (1976) and Downing and Neuringer (1976) found that naive pigeons pecked an illuminated response key the first time it was presented and before pairing with grain if sufficient hopper training was provided.

Not all stimuli have an equivalent effect on behavior, either prior to (Kish, 1966) or after the conditioning process (Revusky \& Garcia, 1970; Seligman, 1970). Stimulus events therefore may derive their reinforcing effectiveness collectively from both conditioned and unconditioned properties (cf. Osborne \& Shelby, 1975).

\section{Self-Reinforcement}

Mahoney and Bandura (1972) found that pigeons trained to peck a briefly illuminated response key before eating continued to respond when the responsedependency for food was removed. They interpreted their data as an animal analogue of human selfreinforcement (Mahoney, 1972). However, responding in Mahoney and Bandura's experiment was maintained only when responses were accompanied by a brief stimulus change. Consequently, responding in this case appears similar to responding maintained in free food experiments; i.e., animals appear to prefer food-plus-stimulus change over food alone.

The data reviewed here show that stimulusreinforcer relationships have a strong effect on behavior; however, the noteworthy point is the magnitude of their effect on behavior. The other conspicuous element of these studies is the lack of a common explanation. Conditioned reinforcement most often is adduced to account for stimulusreinforcer effects on behavior. Although conditioned reinforcement may explain preference for signaled over unsignaled schedules of reinforcement, it has difficulty explaining some free food data and appears to be an unsuitable explanation for autoshaping and automaintenance data (cf. Hearst \& Jenkins, 1974; but see Hursh, Navarick, \& Fantino, 1974; Zentall \& Hogan, 1975). Presently, a single unifying account that encompasses the range of stimulus-reinforcer effects reviewed here is lacking, but future research on sign-tracking behavior may fill this void. A signtracking analysis of the free food phenomenon is not currently possible because of the paucity of data on the effects of systematically varying stimulus conditions correlated with response-dependent food. This deficit itself suggests a productive avenue for future free food research. Data forthcoming from such research not only may allow closure on the free food phenomenon, but may provide data relevant for other areas of research in animal learning as well.

\section{SUMMARY}

A plethora of theoretical accounts have been adduced to explain the free food phenomenon. Some of these include: an intrinsic appeal of performing the operant (Jensen, 1963), responses serving as their own motivation and reinforcement (Neuringer, 1969; Kopp \& Bourland, Note 1), discriminative stimulus properties of reinforcers (Carlson \& Riccio, 1976), environmental competence (Singh, 1970; Stephens, Metze, \& Craig, 1975), arousal properties of reinforcers (Carder, 1972), deprivation (Tarte \& Synder, 1972), habit strength or behavioral persistence (Morgan, 1974a; Tarte \& Synder, 1973), neophobia (Mitchell et al., 1973), Premack's principle (Sawisch \& Denny, 1973), and discrimination (Taylor, 1975). While all of these theories may account for part of the data, none appears to encompass the broad range of experimental findings reviewed here.

It has perhaps been the mistaken belief that free and response-dependent food are equally attractive (reinforcing) that has engendered both surprise and interest in the free food phenomenon. Results of these studies have tempted some (Singh, 1972b) to draw analogies between the propensity of animals to work for reinforcers in the presence of free reinforcers and the human welfare system. Others may have construed such results as an indictment of current learning theories. As shown by the data reviewed above, however, the free food anomaly may be more in perception than in reality; it is the combined reinforcement provided by responsedependent reinforcers and attendant stimulus change that maintains responding for reinforcers in the presence of equivalent free reinforcers. This stimulusreinforcer interaction serves as both a necessary and a sufficient condition for the emergence and main- 
tenance of the phenomenon. ${ }^{2}$ What once appeared as an experimental anomaly now seems accommodated by current learning theory.

Concepts of least effort suggest that animals tend to maximize reinforcement while minimizing effort. An adequate assessment of the relative effortfulness of two alternatives demands that both of the alternatives provide equivalent reinforcement. The failure of most free food experiments to provide such an equivalent has resulted in data that appear contradictory to the least effort concept. However, when the consequences of responding for food or obtaining it freely are made equally reinforcing (e.g., by equating stimulus change conditions for both alternatives), animals show a near exclusive preference for obtaining their food freely.

That animals learn and maintain an operant response for food when free food is available has appeared inconsistent with general tenets of reinforcement theory. The present review, however, shows that reinforcement theory is consonant with these data. Animals respond for food in free food experiments because of the differential reinforcement provided by response-dependent food and correlated stimulus change. Despite procedural differences and the problem of scaling rate of reinforcement for free food, behavior within free food experiments appears similar to behavior observed under conventional choice situations. When responses are reinforced according to concurrent reinforcement schedules, each of which lead to identical reinforcers, animals tend to allocate their responses proportionately to the rate of reinforcement available in one schedule relative to the overall rate of reinforcement available in both schedules (cf. Herrnstein, 1970). If the rate of reinforcement available in one schedule is sufficiently greater than the rate available in the other schedule, exclusive preference for the richer schedule may obtain (Herrnstein, 1958; Herrnstein \& Loveland, 1975). If free food represents a very high "rate of reinforcement," relative to that provided by response-dependent food, then one would expect little responding to occur when stimulus conditions are equalized for both food sources.

Under conventional choice procedures, if additional reinforcers are provided by one schedule, preference for that schedule increases (Fantino \& Herrnstein, 1968). Such a change in preference again appears similar to the effect that results from providing stimulus changes attendant upon responsedependent food. Adding a stimulus change as a consequence of responding appears functionally equivalent to adding "extra" reinforcement to that already provided by response-dependent food. Presumably the reinforcement afforded by food and correlated stimulus change is sufficient to compensate for the difference in rate of reinforcement between the two food sources.
In conclusion, the data from free food experiments appear to be consistent both with the concept of least effort and reinforcement theory.

\section{REFERENCE NOTE}

1. Knopp, J., \& Bourland, G. Rats burpress for food in the presence of free food under a variety of free food conditions. Paper presented at Western Psychological Association, A pril 1972.

\section{REFERENCES}

Alferink. L. A.. Crossman, E. K., \& Cheney. C. D. Control of responding by a conditioned reinforcer in the presence of free food. Animal Learning \& Behavior, 1973. 1, 38-40.

APPEL. J. B. Aversive aspects of a schedule of positive reinforcement. Journal of the Experimental Analysis of Behavior. 1963. 6. $423-428$.

Atnip, G., \& Hothersall, D. The preference of albino rats for free or response-produced food. Bulletin of the Psychonomic Society. 1973, 2. 153-154.

Baenninger, R., \& Mattleman, R. A. Visual reinforcement: Operant acquisition in the presence of a free mirror. Animal Leaming \& Behavior. 1973, 1. 302-306.

Barnes. G. W.. \& Baron. A. Stimulus complexity and sensory reinforcement. Journal of Comparative and Physiological Psychology, 1961, 54, 460-469.

Barnett. S. A. The rat: $A$ study in behavior. Chicago: Aldine, 1963.

Bilbrey. J. L., Patterson, D. D.. \& Winokur, S. Maintenance and autoshaping of keypecking in undeprived pigeons. Bulletin of the Psychonomic Society, 1973, 2, 394-396.

Bindra. D. A motivational view of learning, performance, and behavior modification. Psychological Review, 1974, 81, 199-213.

BLANCHARD. R..\& Honig. W. K. Surprise value of food determines its effectiveness as a reinforcer. Journal of Experimental Psychology: Animal Behavior Processes. 1976. 2. 67-74.

Bolles. R. C. Reinforcement, expectancy, and learning. Psichological Review, 1972, 79. 394-409.

Brown, P. L. d Jenkins, H. M. Auto-shaping of the pigeon's key peck. Joumal of the Experimental Analysis of Behavior, 1968 , 11. 1.8.

Cantor. M. B. Signalled reinforcing brain stimulation facilitates operant behavior under schedules of intermittent reinforcement. Sicience. 1971, 174, 610-612.

Cantor. M. B.. \& LoLordo, V. M. Rats prefer signalled reinforcing brain stimulation to unsignalled ESB. Journal of Comparative and Physiological Psychology, 1970, 71, 183-191.

Cantor. M. B., \& LoLordo. V. M. Reward value of brain stimulation is inversely related to uncertainty about its onset. Journal of Comparative and Physiological Psychology, 1972. 79. 259-270.

CARDER, B. Rats' preference for earned in comparison with free liquid reinforcers. Psychonomic Science, 1972, 26. 25-26.

CARDER, B., \& BeckMAN, G. C. Limitations of "container neophobia" as an explanation of rats" responding for food in the presence of free food. Behavioral Biology. 1975, 14, 109-113.

CARDER, B.. \& BERKowitz, K. Rats preference for earned in comparison with free food. Science, 1970, 167, 1273-1274.

CARlson, C. N., \& Riccio, D. C. Experience with the reinforcer and the preference for earned rather than free reinforcers in rats. Animal Leaming \& Behavior, 1976, 4, 269-272.

COBURN, J. F., \& TARTE, R. D. The effects of rearing environments on the contrafreeloading phenomenon in rats. Journal of the Experimental Analysis of Behavior, 1976, 26, 289-294.

Cohen-Salmon, C., \& Blancheteau, M. Transport et consommation de la norriture dans un parcour expérimental chez le rat blanc. L'Année Psychologique, 1967, 67. 377-384.

Collier, G.. \& Jennings, J. W. Work as a determinant of 
instrumental performance. Journal of Comparative and Physiological Psychology. 1969, 68, 659-662.

D'Aмато, M. R. Derived motives. Annual Review of Psychology, 1974, 25, 83-106.

DaVIDSON, A. Factors affecting keypress responding by rats in the presence of free food. Psychonomic Science, 1971, 24, 135-137.

Davidson, A. B.. \& Davis. D. J. Appetitive control of responding in the presence of free food: Effects of d-amphetamine and fenfluramine. Bulletin of the Psychonomic Society, 1975, 6, 16-18.

Davis, S. F., Beighley, B. G., Libretto, J. S., Mollenhour, M. N., \& Prytula, R. E. Contrafreeloading as a function of early environmental rearing conditions. Bulletin of the Psychonomic Society. 1975, 6. 595-597.

DECAMP, J. E. Relative distance as a factor in the white rats' selection of a path. Psychobiology, 1920, 2, 245-253.

Dember, W. N. Response by the rat to environmental change. Journal of Comparative and Physiological Psychology, 1956, 49. 93.95.

DENNY, M. R. A theory of experimental extinction and its relation to a general theory. In H. H. Kendler \& J. T. Spence (Eds.), Essays in neobehaviorism: A memorial volume to Kenneth W. Spence. New York: Appleton-Century-Crofts, 1971.

Downing, K. \& N Neuringer. A. Autoshaping as a function of prior food presentation. Journal of the Experimental Analysis of Behavior, 1976, 26. 463-469.

Duncan. I. J. H., \& Hughes, B. O. Free and operant feeding in domestic fowls. Animal Behaviour, 1972, 20, 775-777.

EgGer. M. D..\& Miller, N. E. Secondary reinforcement in rats as a function of the stimulus. Joumal of Experimental Psychology, 1962, 64, 97-104.

EgGer, M. D., \& Miller, N. E. When is reward reinforcing?: An experimental study of the information hypothesis. Journal of Comparative and Physiological Psychology, 1963, 56, 132-137.

Enkema, S., Slavin, R., Spaeth, C., \& Neuringer, A. Extinction in the presence of free food. Psychonomic Science, 1972. 26. $267-269$.

Fallon, D., Thompson, D. M.. \& Schild. M. E. Concurrent food and water reinforced responding under food, water, and food and water deprivation. Psychological Reports, 1965. 16. 1305-1311.

Fantino. E., \& Herrnstein. R. J. Secondary reinforcement and number of primary reinforcements. Journal of the Experimental Analysis of Behavior. 1968. 11. 9-14.

Ferster, C. B.. \& Skinner. B. F. Schedules of reinforcement. New York: Appleton-Century-Crofts, 1957.

FowleR. H. Implications of sensory reinforcement. In R. Glaser (Ed.). The nature of reintorcement. New York: Academic Press 1971.

Furedy, J. J., \& Klajner, F. Preference for information about an unmodifiable but rewarding outcome. Journal of Experimental Psychology, 1972, 95, 469-471.

Gengerelli, J. A. Principle of maxima and minima in animal learning. Journal of Comparative and Physiological Psychology, 1930, 11, 193-236.

Gibbon, J.. Berryman, R., \& Thompson, R. L. Contingency spaces and measures in classical and instrumental conditioning. Journal of the Experimental Analysis of Behavior, 1974, 21. 585-605.

Hearst, E., \& Jenkins, H. M. Sign-tracking: The stimulusreinforcer relation and directed action. Austin, Tex: Psychonomic Society, 1974.

Herrnstein, R. J. Some factors influencing behavior in a tworesponse situation. Transaction of the New York Academy of Science, 1958, 21, 35.45.

HerRnstein, R. J. Superstition: A corollary of the principles of operant conditioning. In W. K. Honig (Ed.), Operant behavior: Areas of research and application. New York: AppletonCentury-Crofts. 1966.

HERRNSTEIN. R. J. On the law of effect. Journal of the Experimental Analysis of Behavior, 1970, 13, 243-266.
HERRNSTEIN, R. J., \& Loveland, D. H. Food-avoidance in hungry pigeons and other perplexities. Journal of the Experimental Analysis of Behavior, 1972, 18, 369-383.

Herrnstein, R. J., \& Loveland, D. H. Maximizing and matching on concurrent ratio schedules. Journal of the Experimental Analysis of Behavior, 1975, 24, 107-116

Hershiser, D., \& Trapold, M. A. Preference for unsignalled over signalled direct reinforcement in the rat. Journal of Comparative and Physiological Psychology, 1971, 77, 323-328.

Hothersall, D., HuEY, D., \& Thatcher, K. The preference of rats for free or response-produced food. Animal Learning \& Behavior, 1973, 1, 241-243.

Hull, C. L. Principles of behavior. New York: Appleton-CenturyCrofts, 1943.

Hursh, S. R., Navarick, D. J., \& Fantino, E. "Automaintenance": The role of reinforcement. Journal of the Experimental Analysis of Behavior, 1974, 21, 117-124.

Jennings, W., \& Collier, G. Response effort as a determinant of instrumental performance in the rat. Journal of Comparative and Physiological Psychology, 1970, 72, 263-266.

JENSEN, G. D. Preference for bar pressing over "freeloading" as a function of number of rewarded presses. Journal of Experimental Psychology, 1963, 65, 451-454.

Jensen, G. D., Leung, C. M. \& Hess, D. T. "Freeloading" in the Skinner box contrasted with freeloading in the runway. Psychological Reports, 1970, 27, 67-73.

Kanarek, R. B., \& Collier, G. Effort as a determinant of choice in rats. Journal of Comparative and Physiological Psychology, $1973,84,332-338$.

Kelleher, R. T., \& Gollub, L. R. A review of positive conditioned reinforcement. Journal of the Experimental Analysis of Behavior, 1962, 5, 543-597.

Killeen, P. Response rate as a factor in choice. Psychonomic Science, 1968, 12, 34.

KIsH, G. B. Studies of sensory reinforcement. In W. K. Honig (Ed.), Operant behavior: Areas of research and application. New York: Appleton-Century-Crofts, 1966.

Kleinman, K. M., Mclaughlin, R. J., Gerard, I. C., Bosza, D. A., \& Clipper, R. C. Rats' preference for the more effortful of two responses as a function of prior experience. Psychological Reports, 1976, 38, 931-937.

Knutson, J. F., \& Carlson, C. W. Operant responding with free access to the reinforcer: A replication and extension. Animal Learning \& Behavior, 1973, 1, 133-136.

Koffer, K., \& Coulson, G. Feline indolence: Cats prefer free to response-produced food. Psychonomic Science, 1971, 24, 41-42.

Kopp, J., Bourland, G., Tarte, R. D., \& Vernon, C. R. Acquisition of bar pressing in nondeprived rats. Psychological Record, $1976,26,49-54$.

Kuo, Z. Y. The nature of unsuccessful acts and their order of elimination in animal behavior. Journal of Comparative and Physiological Psychology, 1922, 2, 1-27.

LAMBE, D. R., \& GuY, E. G. A comparison of the preference for free vs. earned food in rats and mongolian gerbils. Proceedings of the Ohio Academy of Science, April 1973.

LARSON, L. D., \& TARTE, R. D. The effects of training and effortfulness on rats' choice behavior in a modified T-maze. Bulletin of the Psychonomic Society, 1976, 7, 506-508.

Leung, C. M., Jensen, G. D., \& Tapley, R. P. "Freeloading" in a runway as a function of amount of training and type of reinforcement schedule. Psychological Reports, 1968, 22, 211-214.

LEwIs, M. Psychological effect of effort. Psychological Bulletin, $1965,64,183-190$.

Lewis, P., Lewin, L., Muehleisen, P., \& Stoyak, M. Preference for signalled reinforcement. Joumal of the Experimental Analysis of Behavior, 1974, 22, 143-150.

Logan, F. A. Incentive. New Haven: Yale University Press, 1960.

MaHongy, M. J. Research issues in self-management. Behavior Therapy, 1972, 3, 45-63.

Mahoney, M. J., \& Bandura, A. Self-reinforcement in pigeons. Learning and Motivation, 1972, 3, 293-303. 
Mclaughin, R. J., Kleinman, K. M., \& Vaughn, L. G. Effects of prior training at leverpressing on rats' subsequent responding for food or water in the presence of free rewards. Proceedings of the 81st Annual Convention of the American Psychological Association, 1973, 8, 845-846. (Summary)

Mitchell, D., ScotT, D. W., \& Williams, K. D. Container neophobia and the rats' preference for earned food. Behavioral Biology, 1973, 9. 613-624.

Mrtchell, D., Williams, K. D., \& Sutter, J. Container neophobia as a predictor of preference for earned foods by rats. Bulletin of the Psychonomic Society, 1974, 4, 182-184.

Moore, J., \& Fantivo, E. Choice and response contingencies. Journal of the Experimental Analysis of Behavior, 1975, 23, 339-348.

Morgan, M. J. Effects of post-weaning environment on learning in the rat. Animal Behaviour, 1973, 21, 429-442.

Morgan, M. J. Resistance to satiation. Animal Behaviour, 1974, 22, 449-466. (a)

Morgan, M. J. Do rats like to work for their food? Learning and Motivation, 1974, 5, 352-368. (b)

Morgan, M. J., Einon, D. F., \& Nicholas, D. The effects of isolation rearing on behavior inhibition in the rat. Quarterly Journal of Experimental Psychology, 1975, 27, 615-634.

NeURINGER, A. J. Animals respond for food in the presence of free food. Science, 1969, 166, 399-401.

Neuringer, A. J. Many responses per food reward with free food present. Science, 1970, 169, 503-504.

Osborne, S. R., \& Shelby, M. Stimulus change as a factor in response maintenance with free food available. Journal of the Experimental Analysis of Behavior, 1975, 24, 17-21.

Pallaud, B. Contribution à l'étude d'une situation de choix la Souris. Revue du Comportement Animal, 1971, 5, 293-297.

Peterson, G. B., Ackil, J. E., Frommer, G. P., \& Hearst, E. Conditioned approach and contact behavior towards signals for food or brain stimulation reinforcement. Science, 1972, 177, 1009-1011.

Powell, R. L. Comparative studies of the preference for free vs. response-produced reinforcers. Animal Learning \& Behavior, 1974, 2, 185-188.

PremaCK. D. Toward empirical behavior laws: I. Positive reinforcement. Psycholgical Review, 1959, 66, 219-233.

RACHLIN, H., \& BAUM, W. M. Effects of alternative reinforcement: Does the source matter? Journal of the Experimental Analysis of Behavior. 1972. 18, 231-241.

Rescorla, R. A., \& SKUCY, J. C. Effect of response-independent reinforcers during extinction. Journal of Comparative and Physiological Psychology, 1969, 67, 381-389.

Robertson, L. C., \& Anderson, S. C. The effects of differing type and magnitude of reward on the contrafreeloading phenomenon in rats. Animal Learning \& Behavior, 1975, 3, 325-328.

RevuskY, S., \& GARCiA, J. Learned associations over long delays. In G. $\mathrm{H}$. Bower (Ed.), The psychology of learning and motivation: Advances in research and theory (Vol. 4). New York: Academic Press, 1970.

Sawisch, L. P., \& Denvy, M. R. Reversing the reinforcement contingencies of eating and keypecking behaviors. Animal Learming \& Behavior, 1973, 1, 189-192.

Seligman, M. E. P. On the generality of the laws of learning. Psychological Review, 1970, 77, 406-418.

SINGH, D. Preference for bar-pressing to obtain reward over free-loading in rats and children. Journal of Comparative and Physiological Psychology, 1970. 73, 320-327.

SINGH, D. Preference for mode of obtaining reinforcement in rats with lesions in septal or ventromedial hypothalamic area. Journal of Comparative and Physiological Psychology, 1972, 80, 259-268. (a)

Singh, D. The pied piper vs. the Protestant ethic. Psychology Today, 1972, 5, 53-56. (b)

Singh, D., \& QUERY, W. T. Preference for work over "freeloading” in children. Psychonomic Science, 1971, 24, 77-79.
SkINNER, B. F. The behavior of organisms. New York: AppletonCentury-Crofts, 1938.

SkInNER, B. F. "Superstition" in the pigeon. Joumal of Experimental Psychology, 1948, 38, 168-172.

Stephens, R. M.. Metze, L. P., \& Craig, J. R. The Protestant ethic effect in a multichoice environment. Bulletin of the Psychonomic Society, 1975, 6, 137-139.

Stiers. M., \& Silberberg, A. Lever-contact responses in rats: Automaintenance with and without a negative response reinforcer dependency. Journal of the Experimental Analysis of Behavior, 1974, 22, 497.506.

Stolz, S. B., \& LOTT, D. F. Establishment in rats of a persistent response producing a net loss of reinforcement. Journal of Comparative and Physiological Psychology, 1964, 57, 147-149.

TARTE, R. D. Earned versus free rewards phenomenon in humans. Proceedings of the 80th Annual Convention of the American Psychological Association, 1972, 7, 880. (Summary)

TARTE, R. D. Extinction of rats' barpressing in the presence of free food. Animal Learning \& Behavior, 1974, 2, 289-292.

TARTE, R. D., \& SNYDER, R. L. Barpressing in the presence of free food as a function of food deprivation. Psychonomic Science, 1972, 26, 169-170.

TARTE, R. D., \& SNYDER, R. L. Some sources of variation in the bar pressing versus freeloading phenomenon in rats. Journal of Comparative and Physiological Psychology, 1973, 84, 128-133.

Tarte, R. D., Townsend, S. G., \& Vernon, C. R. Housing environments and the barpressing vs. freeloading phenomenon in rats. Bulletin of the Psychonomic Society, 1973, 2, 69-71.

Tarte, R. D., Townsend, S. G., Vernon, C. R., \& Rovner, L. An examination of various deprivation-reward combinations in the barpressing vs. freeloading phenomenon in rats. Bulletin of the Psychonomic Society, 1974, 3, 227-229.

TARTE, R. D., \& Vernon, C. R. Rats' barpressing in the presence of free food as a function of fixed-ratio schedules. Bulletin of the Psychonomic Society, 1974, 3, 34-36.

TAYLOR, G. A limitation of the contrafreeloading phenomenon. Psychonomic Science, 1972, 29, 173-174.

TAYLOR, G. T. Discriminability and the contrafreeloading phenomenon. Journal of Comparative and Physiological Psychology, 1975, 88, 104-109.

Thompson, M. E. An experimental investigation of the gradient of reinforcement in maze learning. Journal of Experimental Psychology, 1944, 34, 506-515.

Tolman, E. C. Principles of performance. Psychological Review, 1955, 62, 315-326.

Wallace, P. Complex environments: Effects on brain development. Science, 1974, 185, 1035-1037.

Wallace, R. F., Osborne, S., Norborg, J., \& Fantino, E. Stimulus change contemporaneous with food presentation maintains responding in the presence of free food. Science, 1973, 182, 1038.1039.

WATERS, R. H. The principle of least effort in learning. Journal of General Psychology, 1934, 16, 3-20.

WELKER. W. I., \& KING, W. A. Effects of stimulus novelty on gnawing and eating by rats. Journal of Comparative and Physiological Psychology, 1962, 55, 838-842.

Williams, D. R., \& Williams, H. Automaintenance in the pigeon: Sustained pecking despite contingent nonreinforcement. Journal of the Experimental Analysis of Behavior, 1969, 12, 511-520.

YoshiokA, J. G. Weber's law in the discrimination of maze distance by the white rat. University of California Publication of Psychology, 1929, 4, 155-184.

ZEILER, M. D. Fixed and variable schedules of responseindependent reinforcement. Journal of the Experimental Analysis of Behavior, 1968, 11, 405-414.

Zentall, T. R., \& Hogan, D. E. Key pecking in pigeons produced by pairing keylight with inaccessible grain. Journal of the Experimental Analysis of Behavior, 1975, 23, 199-206. 


\section{NOTES}

1. Methodological differences may account for some of the discrepancy. Tarte and Synder (1972) used independent groups of rats for each deprivation condition, Morgan et al. (1975) shifted their rats from ad-lib feeding to deprivation in the course of the experiment, and Davidson (1971) and Duncan and Hughes (1972) shifted their animals from deprivation to ad-lib feeding.

2. It is assumed here that food-plus-correlated-stimulus change is responsible for both the acquisition and maintenance of food producing operants in the presence of free food. Although a strong argument was made for the role of stimulus change in the maintenance of responding, the contributions of stimulus change in the acquisition of free food responding remains to be investigated systematically.

(Received for publication October 7, 1976; revision accepted May 3, 1977.) 